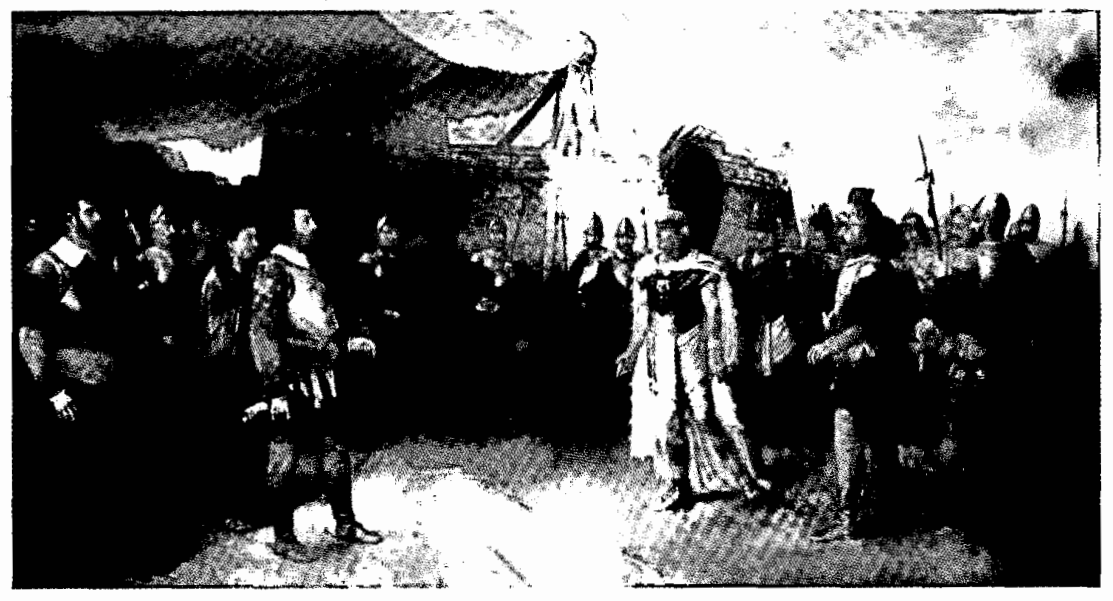




\section{Yolanda Blasco Martel / Anna Carreras Marín}

Yolanda Blasco Martel es licenciada en Historia (1995) y máster en Cooperación y Desarrollo (1997) por la Universidad de Barcelona. Ha sido becaria de investigaciôn del Departamento de Historia e Instituciones Económicas de la Universidad de Barcelona entre 1999-2003 y actualmente es profesora de Historia Económica en la Universitat Internacional de Caralunya e investigadora del proyecto Historia del Banco de Barcelona. Realiza su tesis doctoral sobre las finanzas catalanas a mediados del siglo XIX.

Anna Carreras Marín es licenciada en Economía (1996), y en Antropología Social y Cultural (2000) por la Universidad de Barcelona. Ha realizado trabajos de docencia e investigación como profesora ayudante del Departamento de Historia e Instituciones Económicas de la Universidad de Barcelona entre 1997-2002. También ha impartido clases en la Universitat Pompeu Fabra de Barcelona (2002-2003) en el área de comercio internacional. Actualmente desarrolla su investigación en el proyecto Industrialización y Estrategias Empresariales en España, 1780-1936.

\section{Resumen}

Este artículo analiza la estructura comercial española con Cuba en los años previos e inmediatamente posteriores a la independencia cubana de 1898. Si bien en términos agregados el fin de la colonia supone la desaparición de importantes vínculos comerciales bilaterales, el análisis de algunas categorías de productos pone de relieve el mantenimiento e incluso incremento de la exportación española a Cuba de algunos de estos productos. La hipótesis para explicar este comportamiento anómalo se basa en la presencia de estrategias de diferenciación de productos cuyo éxito se asocia con las preferencias por lo "español" de un segmento de la demanda cubana.

Palabras clave:

Diferenciación, competitividad, comercio internacional, comercio hispano-cubano, path dependence, colonialismo, preferencias del consumidor.

\section{Abstract}

This article analyzes the structure of Spanish trade with Cuba during the period leading up to and immediately after Cuban independence in 1898. Although in overall terms, the loss of the colony meant the disappearance of major bilateral trade links, an analysis of certain groups of products shows that Spanish exports to Cuba of some of the latter were maintained or actually increased. The hypothesis for explaining this anomalous behavior is based on the presence of product differentiation strategies whose success is linked to the preference for "Spanish goods" of a certain sector of Cuban demand.

\section{Key words:}

Differentiation, competitiveness, international trade, Spanish-Cuban trade, path dependence, colonialism, consumer preferences.

Fecha de recepción: junio de 2003

Fecha de aceptación: octubre de 2003 


\title{
Las exportaciones de España a Cuba (1891-1913): pervivencias históricas en la demanda cubana de productos españoles
}

\author{
Yolanda Blasco Martel \\ Anna Carreras Marin*
}

\section{INTRODUCCIÓN}

$\mathbf{Q}^{1}$ 1 presente trabajo parte de considerar la importancia que tuvieron, para el comercio exterior español, las exportaciones a Cuba a lo largo de la segunda mitad del siglo XIX. La caída del comercio hispano-cubano tras la independencia de Cuba en 1898 es un hecho ampliamente aceptado, sin embargo, al profundizar en el nivel de desagregación de los datos nos hallamos con productos que no sólo mantuvieron su presencia en la isla después de la quiebra colonial, sino que la incrementaron. Al preguntarse por qué se produce este fenómeno es inevitable pensar en términos de competitividad de los productos de exportación españoles. Los tejidos de algodón representan un caso específico de esta realidad dual que emerge a partir de las distintas

* Las autoras agradecen al proyecto Industrialización y Estrategias Empresariales en España 17801936, DGI, Ministerio de Ciencia y Tecnología de España, dirigido por el doctor Carles Sudrià, el espacio que les ha ofrecido para desarrollar este trabajo, así como los comentarios recibidos en el III Congreso de Historiadores Latinoamericanistas, Pontevedra, 2001 y en el VII Congreso de la Asociación de Historia Económica, Zaragoza, 2001. Igualmente desean agradecer las sugerencias aportadas por los tres referentes anónimos. escalas de análisis utilizadas. Así, en un marco de caída generalizada de la exportación agregada, algunas categorías de productos concretos (los tejidos de algodón de color entre ellos) experimentaron incrementos significativos.

En este texto mantenemos que, en lo que se refiere al relativo incremento de la exportación de algunos productos españoles, Cuba no es un ejemplo de adaptación competitiva de la industria exportadora española, sino que fueron las características específicas del mercado cubano las que permitieron un éxito exportador tan localizado. Estas características estarían en estrecha relación con el pasado colonial a través de las pautas de consumo transferidas a Cuba desde España, ya fuera a causa de la demanda directa de los emigrantes españoles, ya fuera a través de los consumidores cubanos.

El estudio de la demanda cubana y española se ha realizado distinguiendo entre los niveles de renta y las preferencias de los consumidores desde un enfoque fundamentalmente descriptivo, ya que los datos disponibles imposibilitan la aplicación de la técnica econométrica. A través de la información cualitativa de los informes comerciales de la época se apunta que el factor clave residiría en las preferencias por "lo español" de un segmento 
de la demanda cubana. Estas preferencias podrían estar relacionadas, bien con la colonia española residente en la isla, bien con la adaptación de la población cubana a los gustos españoles tras la larga presencia colonial.

Los datos utilizados en el presente trabajo proceden de las Estadísticas del comercio exterior de España (estadísticas oficiales), las cuales, pese a las críticas que en el texto se detallan, siguen siendo la fuente primordial para el estudio del comercio exterior español. El periodo que abarca este trabajo está determinado por el objetivo de analizar el impacto de la independencia sobre el comercio hispanocubano. El arancel proteccionista de 1891 fija el inicio del periodo. Los años previos a la primera guerra mundial cierran el estudio, ya que el impacto del conflicto modificó sustancialmente las pautas de las relaciones económicas internacionales. ${ }^{1}$

El trabajo se organiza en cuatro apartados y las conclusiones. En el primer apartado se ofrecen, brevemente, las características del comercio exterior español durante la última década del siglo XIX y la primera del $\mathrm{xx}$, poniéndose de relieve la importancia relativa del mercado cubano incluso después de 1898. En el segundo punto se evalúa el impacto de la independencia para los principales productos de exportación, distinguiéndose entre aquellos que experimentaron un claro declive y los que mantuvieron, y aun aumentaron, sus cuotas de participación en el mercado cubano. En el tercero se analiza la evolución de la exportación españo-

${ }^{3}$ Los datos de Kertesz, que permiten la comparación internacional, refieren a 1913, mientras que el estudio del comercio hispano cubano se ciñe a los 20 años que van de 1891 a 1910. la a Cuba, a través de los tejidos de algodón blancos, por un lado, y teñidos y estampados, por el otro. En el último apartado se reflexiona acerca de la pervivencia de elementos de carácter histórico y su importancia en la explicación de la aparente competitividad de algunos productos mediante un análisis de los mercados interiores de España y Cuba; por último se incluye un apartado de conclusiones.

\section{EL COMERCIO EXTERIOR ESPAÑOL (1891-1913)}

En el periodo que abarca este trabajo, el comercio exterior español estuvo dominado por los alimentos y las materias primas, aunque, como puede comprobarse en el cuadro 1, hacia el final del periodo las manufacturas habían incrementado su participación.

En 1913, Alemania, Francia, Gran Bretaña e Italia mantenían un peso de las manufacturas más alto que el español. En todos estos países, ésas rondaban $65 \%$, con excepción de Italia, cuyas exportaciones de textiles sólo alcanzaba $40 \%$ del total. En España, en los primeros años de la década de 1920, las exportaciones de alimentos estaban por encima de $50 \%$, mientras que las manufacturas se mantuvieron alrededor de $20 \%$ del total de las exportaciones. Este comportamiento español es atípico en relaciốn con el que manifestaron las exportaciones europeas. $\mathrm{El}$ aumento relativo del papel de las manufacturas al final del periodo está relacionado con la caída de la exportación del vino, en el apartado de los alimentos. ${ }^{2}$

${ }^{2}$ Pinilla y Ayuda, "Political", 2002, p. 57, atribuyen la crisis vinị́cola a las medidas proteccionistas 


\section{SECUENCIA}

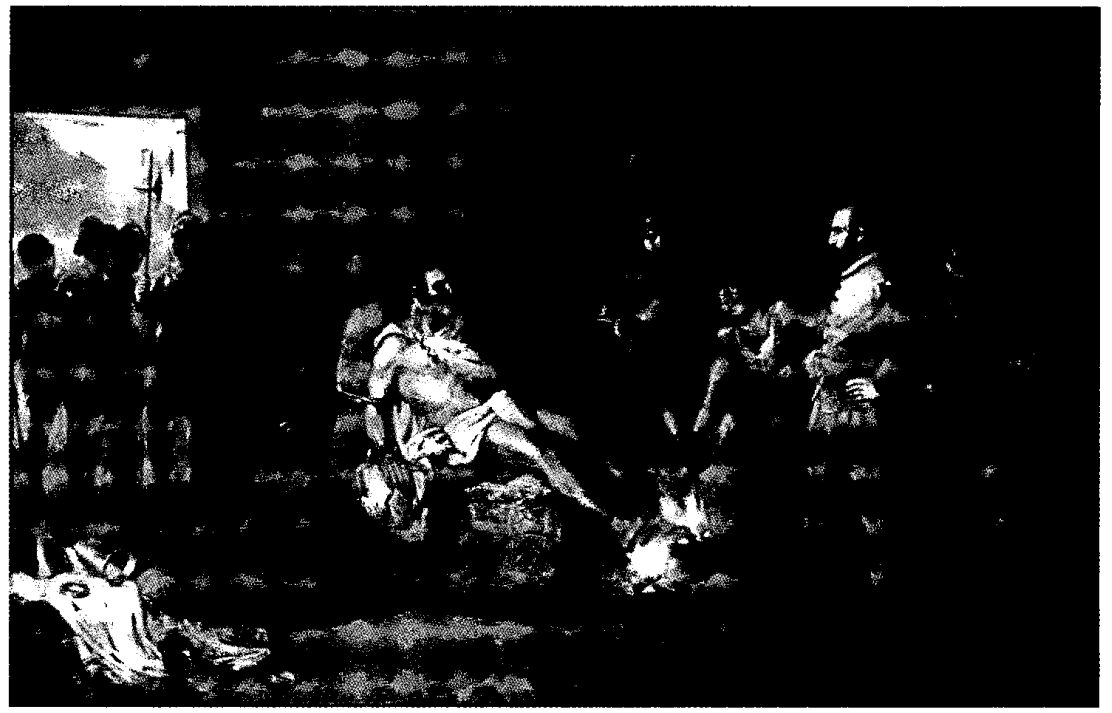


Cuadro 1. Composición de las exportaciones españolas (1890-1913)

Periodo

1890-1894

1910-1913
Alimentos

$49.5 \%$

$43.3 \%$
Materias primas

$36.1 \%$

$32.3 \%$
Manufacturas

$14.4 \%$

$24.4 \%$

Fuente: Prados, "Evolución", 1984, p. 139.

Los principales productos de la exportación española, que representaban aproximadamente $60 \%$ del total de las exportaciones entre 1890 y 1913 , están reflejados en el cuadro 2. En la evolución de este conjunto de exportaciones destaca la pérdida de importancia del vino al igual que la creciente participación de otras categorías de producto como el hierro mineral, el corcho, el cobre, las naranjas, el aceite y las conservas. La similar participación de los tejidos de algodón esconde la desaparición de los tejidos blancos y la extensión exportadora de los tejidos de color, como más adelante se verá. El aumento de los porcentajes representados por estos productos manifiesta el proceso de diversificación de productos de la estructura exportadora española a partir de 1898, fenómeno señalado por distintos autores. ${ }^{3}$

de los principales mercados importadores, así como a la creciente producción vinícola en países no europeos (especialmente Argelia, pero también Argentina, Estados Unidos, Brasil y Uruguay). De este modo, si bien de 1885 a 1894 España representaba $17.48 \%$ de la producción mundial de vino, de 1910 a 1914 su participación se había reducido a $9.5 \%$. En el mercado cubano, la política proteccionista estadunidense, en el sector del vino, debe haber sido el factor determinante de la caída de la exportación española en la isla.

${ }^{3}$ Sudrià, "Exportación", 1983; Prados, "Evolución", 1984; Prados y Tortella, "Tendencias", 1983; Tena, "Protección", 1992; Serrano, "Sector", 1997.
Esta variedad de productos vendría acompañada de una diversificación geográfica, hecho que se constata en el análisis de los principales socios comerciales de España en el periodo considerado (véase gráfica 1). Los productos de exportación españoles desde el último tercio del siglo XIX se dirigían fundamentalmente hacia Francia, Gran Bretaña y Cuba. Los dos primeros países se alternaban en la primera posición como socios comerciales españoles, significando -hasta los primeros años del siglo $\mathrm{XX}$ - el destino de más de $50 \%$ de las exportaciones españolas. Cuba, colonia española hasta 1898 , recibía entre 15 y $17 \%$ durante el periodo previo a la independencia. Sin embargo, a partir de 1900 apareció una mayor diversificación en los destinos de los productos españoles.

A partir de la independencia cubana se modificó significativamente la composición de los socios comerciales de España. Destaca, fundamentalmente, la emergencia de Alemania y Estados Unidos entre los principales mercados importadores de productos españoles, a la vez que se hizo notar una drástica caída del mercado cubano.

A pesar del claro declive del mercado antillano (el cual redujo su participación en la exportación española $9.4 \%$ de 1890 a 1913), su permanencia entre los princi- 
Cuadro 2. Porcentaje de la composición de la exportación española (1890-1913)

$\begin{array}{lcc}\text { Productos } & 1890-1894 & 1910-1913 \\ \text { Vino } & 23.1 & 8 \\ \text { Plomo } & 7 & 6.7 \\ \text { Hierro (mineral) } & 5.9 & 8.6 \\ \text { Tejidos algodón } & 4.7 & 4.5 \\ \text { Corcho } & 3 & 4.3 \\ \text { Cobre (mineral) } & 3 & - \\ \text { Cobre (metal) } & 2.7 & 4.2 \\ \text { Pasas } & 2.4 & - \\ \text { Naranjas } & 2.1 & 5.5 \\ \text { Aceite } & 2 & 3.8 \\ \text { Calzado } & 1.7 & - \\ \text { Ganado } & 1.7 & 1.9 \\ \text { Lana } & 1.2 & 1.6 \\ \text { Uvas } & 1.2 & 1.7 \\ \text { Almendras } & 1.1 & 2 \\ \text { Conservas } & - & 4.2 \\ \text { Pieles y cueros } & - & 1.8 \\ \text { Cebollas } & - & 1.6 \\ \text { Otros productos } & 37.20 & 39.60\end{array}$

Fuente: Prados, "Evolución", 1984.

pales socios comerciales de España al final del periodo se hace difícil de comprender sin acudir a las pervivencias de un pasado colonial en un claro proceso de histéresis o path dependence de tipo histórico. ${ }^{4}$

\footnotetext{
${ }^{4}$ Nos referimos a las teorías de la path dependence o dependencia de la trayectoria según las primeras versiones de $P$. David, donde se subraya especialmente el papel del accidente histórico como determinante de procesos acumulativos que configuran ciertas realidades económicas en un momento posterior del tiempo, y no tanto a los ulteriores desarrollos de estas teorías en sus aplicaciones a la innovación tecnológica. Las referencias clásicas de esta teoría en el sentido que aquí la usamos son de David, "Clio", 1985, y
}

El papel que ocupaba Cuba estuvo determinado por los acontecimientos de 1898. El fin del imperio colonial español se vio reflejado también en sus relaciones comerciales con la isla. Sin embargo, durante todo el periodo, Cuba se mantuvo entre los principales destinos de las exportaciones españolas. En 1910, países como Alemania y Estados Unidos se per-

"Understanding", 1986, en las que explícitamente el autor declara que el ejemplo de los teclados (QWERTY) tenía el objetivo original de introducir la importancia de la historia en los análisis económicos de un modo que no causara rechazo a un público de economistas. 
Gráfica 1. Socios comerciales de España (1890-1913)

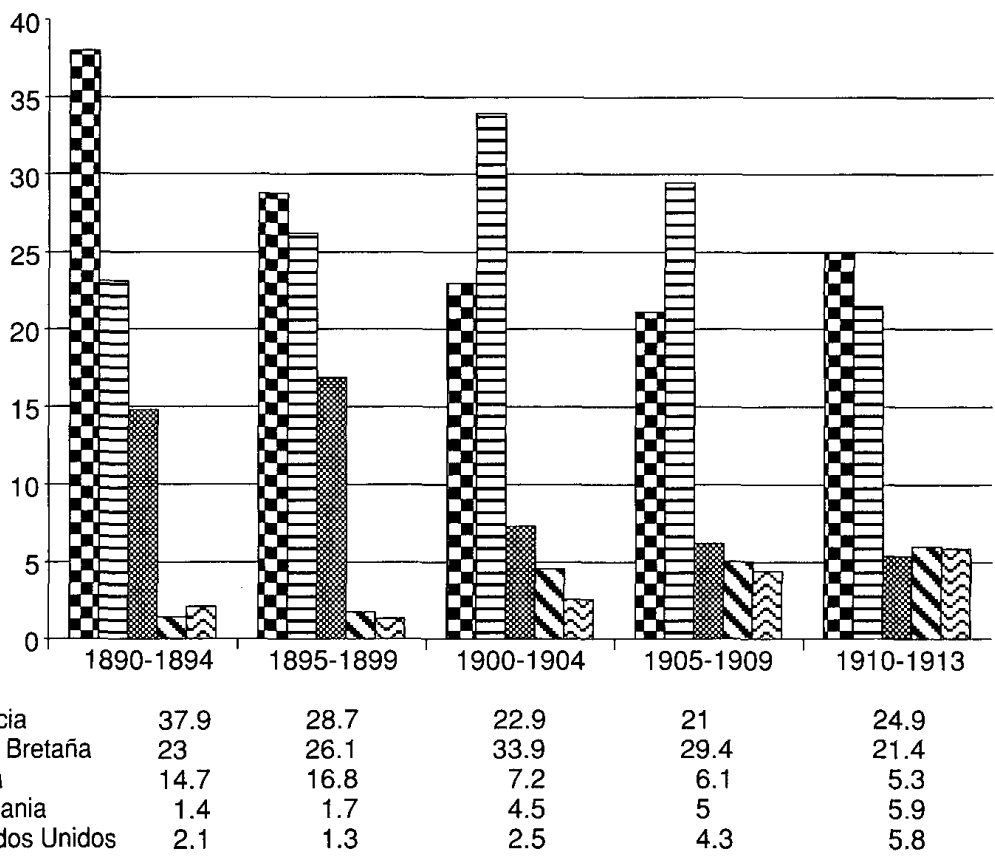

Fuente: Tena, "Comercio", 1989.

filaban como destinos opcionales de la isla caribeña. En el cuadro 3 puede observarse la evolución, en valores absolutos y relativos, de las exportaciones españolas a Cuba sobre el total de exportaciones españolas.

Las exportaciones a Cuba no siguieron el mismo rumbo que el total de las exportaciones españolas. Mientras las primeras sufrieron una pronunciada caída a lo largo del periodo, el total de la exportación española creció. Durante los primeros años de la década de 1890 , tras la aplicación del arancel y antes del inicio de la guerra, Cuba había aumentado su participación en el total de exportaciones debido a su carácter de colonia española y a su claro papel de mercado cautivo. Esta situación se invirtió drásticamente a partir de 1899 con la ruptura del vínculo colonial (véase gráfica 2).

Los datos de las estadísticas oficiales españolas ponen de relieve, sin lugar a duda, la caída de la exportación tras la independencia de Cuba como colonia. Pero 
Cuadro 3. Total de exportaciones españolas y exportaciones a Cuba en pesetas corrientes (1891-1910)

$\begin{array}{lr}\text { Año } & \text { Exportaciones a Cuba } \\ 1891 & 114860362 \\ 1892 & 145319355 \\ 1893 & 127924211 \\ 1894 & 117061881 \\ 1895 & 136261640 \\ 1896 & 255904875 \\ 1897 & 252924875 \\ 1898 & 67441726 \\ 1899 & 73787905 \\ 1900 & 56802102 \\ 1901 & 58497375 \\ 1902 & 52000328 \\ 1903 & 66092854 \\ 1904 & 80555142 \\ 1905 & 73092970 \\ 1906 & 60533824 \\ 1907 & 63399413 \\ 1908 & 50177740 \\ 1909 & 53631159 \\ 1910 & 55669794\end{array}$

Exportaciones españolas

932200000
759500000
709700000
672900000
805000000
1023300000
1074900000
918009000
864400000
836100000
790500000
850006000
946000000
956700000
938900000
937600000
922000000
969500000
1019300000
1075300000

Exportaciones a Cuba sobre el total de exportaciones"

12.32

19.13

18.02

17.39

16.92

25.00

23.53

7.34

8.53

6.79

7.40

6.11

6.98

8.42

7.78

6.45

6.87

5.17

5.26

5.17

${ }^{a}$ Los datos pertenecen a las Estadísticas del comercio exterior de España y están expresados en términos corrientes. En estos datos se incluye la plata, especialmente relevante en los años de la guerra de independencia. Compárese con la gráfica 2, donde se excluye este producto. El total de las exportaciones españolas se tomó de Tena, "Comercio", 1989, y aparecen redondeados; no se usan los cálculos de este autor para comparar con los datos de las exportaciones a Cuba. A pesar de las numerosas críticas que han recibido las estadísticas comerciales (Álvarez, "Historia", 1943, y "Balanzas", 1945; también Gwinner, "Política", 1973) es imposible realizar un estudio particularizado por productos sin recurrir a ellas. Por otra parte, tiende a pensarse que dichas estadísticas no merecen el trato tan denigrante que han tenido. Prados, "Serie", 1986, ha hecho el ejercicio de medir la variación de las cifras que las mismas ofrecen. Lo que parece estar claro es que las estadísticas arrojan cierta diferencia en la medición de importaciones y exportaciones así como en general una tendencia a la baja en las exportaciones. 


\section{SECUENCIA}

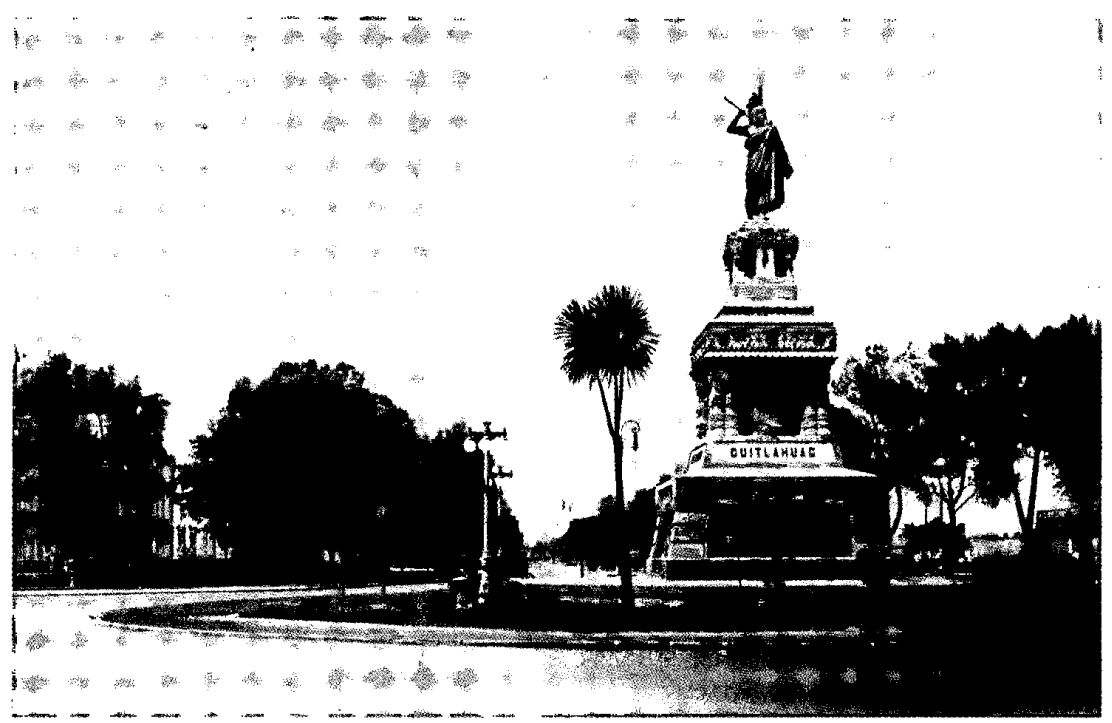


Gráfica 2. Exportaciones de España a Cuba (1891-1910) (en pesetas constantes, $1900=100$ )

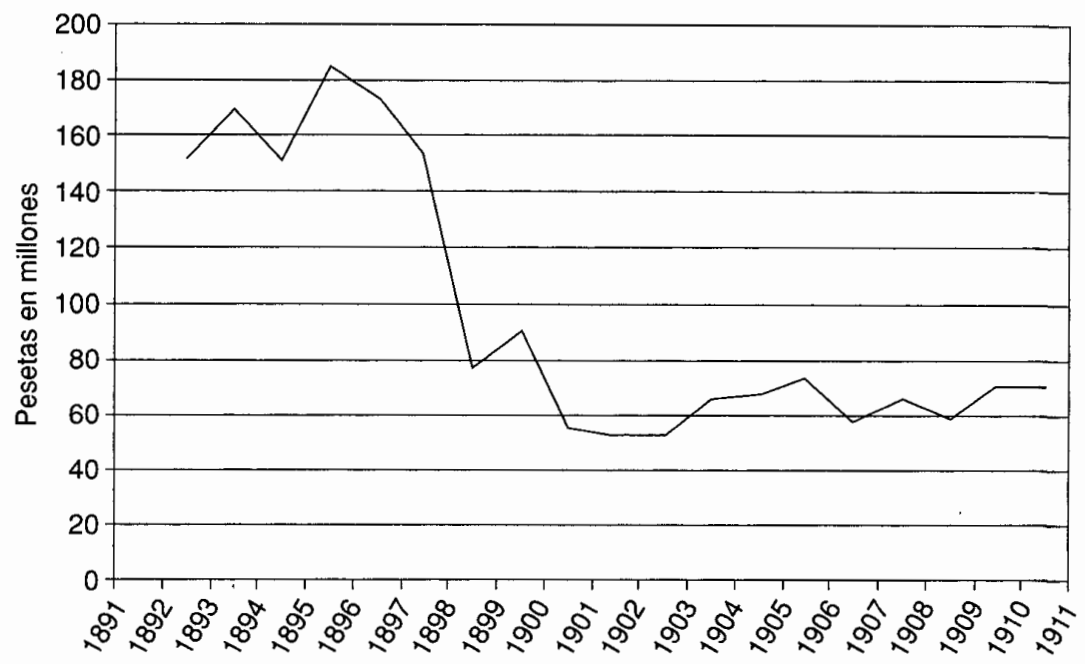

Serie deflactada basada en las Estadísticas del comercio exterior de España, excluyendo la plata. Para deflactar los valores de las exportaciones se ha utilizado el índice de precios ofrecidos por Tena "Comercio", 1989, p. 352. Es un índice aproximado, ya que la composición de las exportaciones de España a Cuba no se reflejan exactamente en el mismo. Sin embargo, esta aproximación puede servir, ya que ni la representación gráfica resultante de mantener los datos en pesetas corrientes ni la aplicación de otros deflactores modifican sustancialmente la caída experimentada por las exportaciones españolas a Cuba tras la guerra. Aparecen algunas diferencias en el momento de la guerra entre los datos que incluyen las exportaciones de plata y los que las excluyen.

Fuente: Estadísticas del comercio exterior de España, 1891-1910.

junto a esta evidente disminución, contrasta la permanencia de Cuba entre los primeros socios comerciales de España al final del periodo considerado. Si en el análisis de la exportación neutralizamos el efecto tamaño de los distintos países implicados mediante la división de la exportación española entre el tamaño de la población de cada país de destino, obtenemos una medida de la intensidad de importación de cada uno de los socios comerciales de España, recogida en el cuadro $4 .^{5}$

Con estos datos resulta evidente que, dado el pequeño tamaño de la isla de

${ }^{5}$ El concepto de intensidad importadora procede de los estudios de Burenstam, Essay, 1961, aunque este autor pondera el tamaño de cada país importador a través del PIB. En el presente caso, se ha optado por ponderar con base en la población, debido a la falta de datos del PIB para el caso cubano. 
Cuadro 4. Intensidad importadora de los socios comerciales de España (1910-1913)

$\begin{array}{lrcc}\text { Socios comerciales } & \begin{array}{c}\text { Población } \\ \text { (millones) }\end{array} & \begin{array}{c}\text { Exportación } \\ \text { (millones de pesetas) }\end{array} & \begin{array}{c}\text { Intensidad de importación } \\ \text { (pesetas por persona) }\end{array} \\ \text { Francia } & 39.50 & 297.56 & 7.53 \\ \text { Gran Bretaña } & 46.00 & 255.73 & 5.56 \\ \text { Alemania } & 67.50 & 70.51 & 1.04 \\ \text { Estados Unidos } & 100.20 & 69.31 & 0.69 \\ \text { Cuba } & 2.47 & 63.34 & 25.60\end{array}$

Fuentes: Tena, "Comercio", 1989, y Kertesz, Textilindustrie, 1917.

Cuba en relación con los otros países importadores de productos españoles, esta importación resulta excepcionalmente grande. Mientras que cada francés consume más de siete pesetas en productos españoles en 1913, cada cubano gasta más del triple. De este modo, queda constatada la presencia de una significativa intensidad importadora de Cuba con España más allá de la disolución de sus vínculos de dependencia colonial.

EL IMPACTO DE LA INDEPENDENCIA EN LA COMPOSICIÓN DEL COMERCIO CON CUBA

La derrota de España en la guerra de 1898 marcó también el fin de su imperio colonial. En un primer momento, entre los coetáneos primó el sentimiento de humillación: una nación prácticamente nueva en la escena internacional (Estados Unidos) propinó el último manotazo a un viejo imperio.

Esta percepción derivó en el pesimismo finisecular, el regeneracionismo y diferentes miradas acerca del destino del país. ${ }^{6}$ Cuando la guerra se supo perdida, comenzó a pensarse en la posibilidad cierta de ver desaparecer el mercado colonial, preocupación que inclinó a los hombres de fines del siglo XIX a suponer que dicha pérdida traería tanto una crisis industrial (asociada con la desaparición de los mercados exteriores) como una caída del consumo privado, resultado del coste de las guerras. ${ }^{7}$ Sin embargo, esos temores a potenciales dificultades pronto parecieron disiparse.

En mayo de 1899, en un manifiesto de la organización patronal catalana Fomento del Trabajo Nacional, se reconoció que el fin de la guerra no derivó en la grave crisis augurada. Pablo de Alzola, hombre representativo de la metalurgia vasca y director general en el Ministerio dirigido por Gasset en 1900, sostuvo que afectó a la industria textil, pero no gravemente,

\footnotetext{
${ }^{6}$ Pueden encontrarse referencias a estos aspectos en Pan, "Atraso", 1998.

${ }^{7}$ Preocupación expresada por la Diputación Provincial de Barcelona en mayo de 1898, Maluquer, "Economistas", 1997. Véase además Maluquer, "Consecuencias", 1998.
} 
ya que el mercado interno absorbió los excedentes sin dificultad. El economista español Antonio Flores de Lemus señaló, además, que la situación de posguerra se consideró un periodo de expansión y prosperidad general. ${ }^{8}$ Así, en lo inmediato, los efectos económicos parece que no se dejaron sentir y el sistema político restaurador, instalado en 1874 , continuó su andadura.

El papel del comercio exterior en el crecimiento económico español ha sido estudiado extensamente en la historiografía española. ${ }^{9}$ Leandro Prados no da excesiva importancia a las independencias antillana y filipina, considerando que

las naciones de Europa noroccidental, en particular Francia y Gran Bretaña, fueron los nuevos mercados que sustituyeron a los de las colonias hispanoamericanas. Las industrializaciones en curso de estas naciones supusieron una demanda creciente de materias primas y productos alimentario. ${ }^{10}$

Serrano Sanz, quien se ha ocupado exhaustivamente de la política comercial de la Restauración, señala que

[l]a edad de oro de las exportaciones españolas, el último tercio del xrx, se explica por la confluencia de tres hechos extraordinarios: filoxera francesa, explotación acelerada de la riqueza minera y, en los últimos años, las

${ }^{8}$ Véase al respecto Maluquer, "Economistas", 1997, y España, 1999.

${ }^{9}$ Uno de los primeros trabajos al respecto fue el de Maluquer, "Mercado", 1974. El mismo autor, $a$ posteriori, publicó un análisis sobre los resultados económicos de la guerra, Maluquer, "Consecuencias", 1998.

${ }^{10}$ Prados, "Evolución", 1984, p. 145. ventas de manufacturas a las colonias. Después, el agotamiento de la coyuntura mine$\mathrm{ra}$, la rigidez al alza de las ventas de productos agrícolas, enfrentados a un mundo de creciente proteccionismo en ese campo, y la insuficiente modernización de la industria, lejos aún de las condiciones requeridas para exportar, explican con creces los términos sectoriales del problema. ${ }^{11}$

Por otro lado, Antonio Tena ${ }^{12}$ remite a las políticas económicas que aislaban al país del concierto internacional (se refiere principalmente a la marginación del sistema monetario internacional y a las altas barreras arancelarias para los productos manufacturados) como las causas que impidieron que España, entre 1890 y 1913, aprovechase la fase de expansión de la economía internacional para recuperarse. $\mathrm{Al}$ bert Carreras ${ }^{13}$ también ha reflexionado sobre la coyuntura económica de España en el cambio de siglo. El año 1898 fue de buenas cosechas y los años siguientes estuvieron acompañados por el retorno de los capitales antillanos, lo que implicó que, entre 1898 y 1902, se viviese un auge inversionista en el país. Además, la depreciación de la peseta colaboró al crecimiento de las exportaciones. Así, los costes de la guerra no se pagaron de forma inmediata, sino a lo largo de la década 1899-1909. "y muy probablemente sea la causa del insuficiente crecimiento de la economía española durante esos años. Crecimiento insuficiente, pero no inexistente. El Desastre en mayúsculas tuvo su paliativo en una economía expansiva." ${ }^{4}$

1 "Serrano, "Sector", 1997, p. 311.

12 Tena, "Protección", 1992.

${ }^{13}$ Carreras, "Coyuntura", 1999.

${ }^{14}$ 1bid., p. 305. 
El presente análisis contempla el "desastre" de 1898 como un proceso dinámico, cuyo impacto quedaría repartido a lo largo de los años que precedieron a la primera guerra mundial. Según este enfoque, las relaciones entre Cuba y España no se rompieron definitivamente tras la guerra colonial, a pesar de que el año 1898 supone un punto de ruptura en la serie de exportación agregada, tal y como ponen de manifiesto las Estadísticas del comercio exterior de España. En términos desagregados, el análisis de la exportación por categorías de productos muestra cómo el impacto de la independencia fue desigual. ${ }^{15}$

El análisis de la composición de la exportación española a Cuba pone de relieve que no se puede extrapolar la caída de la exportación a todos los sectores (véase cuadro 5). A partir de una muestra de productos representativos de la exportación española a Cuba a lo largo del periodo, se observa cómo las principales exportaciones en 1891 de calzado (14.77\%), tejidos $(10.99 \%)$ y vino $(10.22 \%)$ continuaron ocupando las primeras posiciones en 1910 , aunque el calzado (11.97\%) y el vino $(9.13 \%)$ perdieron peso relativo, mientras que aumentó el de los tejidos $(17.19 \%)$, las conservas alimenticias $(9.29 \%)$ y el aceite $(8.13 \%){ }^{16}$

${ }^{15}$ Blasco, "Exportaciones", 2001.

${ }^{16}$ Puede verse una referencia de las exportaciones de estos productos a Cuba en ibid. Igualmente existen trabajos sobre estos productos, entre ellos: Miranda, Industria, 1997, ofrece importante documentación respecto a la evolución del sector del calzado. Para la industria conservera véase el estudio de Martínez, "Industria", 1989; sobre las exportaciones de aceite consúltese Ramon, "Exportación", 2000, y sobre el sector textil: Sudrià, "Exportación", 1983.
En la evolución de la composición de la exportación española a Cuba destaca especialmente el incremento de las exportaciones de conservas alimenticias $(37.74 \%)$ y de aceite $(12.65 \%)$. Las exportaciones de tejidos de algodón (el principal producto de exportación a Cuba en 1910) se habrían reducido a $75.83 \%$ respecto de 1891, reducción moderada que esconde un cambio importante: la sustitución casi total de la exportación de tejidos de algodón blancos por la exportación de tejidos de algodón de color, de mayor valor añadido. ${ }^{17}$

De este modo se constata cómo los sectores que lograron mantener e incluso incrementar su exportación a Cuba tras el fin del vínculo colonial implicaron productos muy dependientes de las preferencias de los consumidores (conservas, aceite y tejidos de colores). El vino, que reduce su participación en la exportación española a Cuba, a pesar de ser un producto claramente relacionado con los gustos del consumidor, es un caso excepcional y está relacionado, como ya se mencionó, con los avatares padecidos por este producto .de exportación en la época. Por otro lado, los sectores que fueron incapaces de soportar la competencia de los nuevos socios comerciales de Cuba se caracterizaron por implicar productos de bajo precio y de carácter estandarizado, ${ }^{18}$ para los que las

${ }^{17}$ El cambio en la estructura exportadora de tejidos de algodón hacia un aumento del valor añadido no es exclusivo del mercado cubano, sino que se produce también a nivel agregado, según señala Sudrià, "Exportación", 1983.

${ }^{18}$ Un caso excepcional son las alpargatas, cuya exportación se incrementó espectacularmente a partir de la guerra de 1898, manteniéndose en niveles superiores a los prebélicos en los años posteriores. Esto se relaciona, en primer lugar, con el avitual lamiento 
Cuadro 5. Productos de exportación a Cuba

\begin{tabular}{lrlrrrrr} 
& \multicolumn{2}{c}{1891} & \multicolumn{2}{c}{1898} & \multicolumn{2}{c}{1910} \\
Productos & \multicolumn{1}{c}{$\begin{array}{c}\text { Pesetas } \\
\text { corrientes }\end{array}$} & Kilogramos & \multicolumn{1}{c}{$\begin{array}{c}\text { Pesetas } \\
\text { corrientes }\end{array}$} & Kilogramos & $\begin{array}{c}\text { Pesetas } \\
\text { corrientes }\end{array}$ & Kilogramos \\
Jabón duro & 3587080 & 5978467 & 2110150 & 4057981 & 1154316 & 2219839 \\
Calzado & 16968224 & 1060514 & 7966440 & 315971 & 6661865 & 291934 \\
Tejidos algodón & 12619849 & $2804411^{\text {a }}$ & 12265027 & 2010009 & 9569036 & 1373550 \\
Aceite & 4018500 & 4320968 & 2820966 & 3318784 & 4526788 & 4526788 \\
Vino & 11733856 & 46935424 & 6411356 & 32056779 & 5081839 & 20327354 \\
Conservas & 3755215 & 2503477 & 5521211 & 3680807 & 5172460 & 4324706 \\
Total & 114860362 & & 67441726 & & 55669794 &
\end{tabular}

${ }^{a}$ Sólo tejidos blancos.

Fuente: Estadísticas del comercio exterior de España, 1891-1910.

ventajas de costes de los productos estadunidenses resultarían fulminantes. La corroboración de este hecho parece indicar que la estrategia competitiva viable ante el aumento de competencia en el mercado cubano fue la estrategia de la diferenciación de producto, para la que los tejidos de algodón representan un claro ejemplo.

\section{LA DEMANDA CUBANA DE TEJIDOS ESPAÑOLES DE ALGODÓN}

En el caso de los tejidos de algodón, numerosos estudios han puesto de relieve que los mercados internacionales, en el periodo previo a la primera guerra mun-

del ejército durante la contienda y, posteriormente, con el tipo de inmigración española que acudió a Cuba a principios del siglo $\mathrm{xx}$, trabajadores del campo y obreros. A pesar de que se trata de un producto de bajo valor añadido, su pervivencia está directamente relacionada con las preferencias por los productos españoles de un sector del mercado cubano, tal y como se argumenta en este artículo. dial, funcionaban en competencia monopolística. Esto era debido, por un lado, a la presencia de economías de escala externas en el sector textill, ${ }^{19} \mathrm{y}$, por otro, a las estrategias de diferenciación de producto seguidas por los principales productores. ${ }^{20}$ De este modo, no resulta extraño constatar que, en el mercado cubano, España siguiera las tendencias internacionales $y$, reaccionando ante un aumento de la competencia, respondiera con estrategias de diferenciación de producto. Lo que resulta sorprendente es el grado de relativo éxito logrado por los tejidos españoles en Cuba, en contraste con su fracaso en el resto de los mercados abiertos a la competencia. ${ }^{21}$

${ }^{19}$ Un estudio reciente sobre las economías de escala externas en el sector textil británico es el de Broadberry y Marrison, "External", 2002.

${ }^{20}$ Sandberg, "Movements", 1968; Temin, "Product", 1988; Brown, "Imperfect", 1995; Carreras, "Mercado", 2001.

${ }^{21}$ Aunque los datos que aporta Kertesz son indicativos de este fracaso exportador español en los mercados abiertos a la competencia, no en todos tuvo la misma intensidad. Así, en algunos países con fuerte 


\section{SECUENCIA}

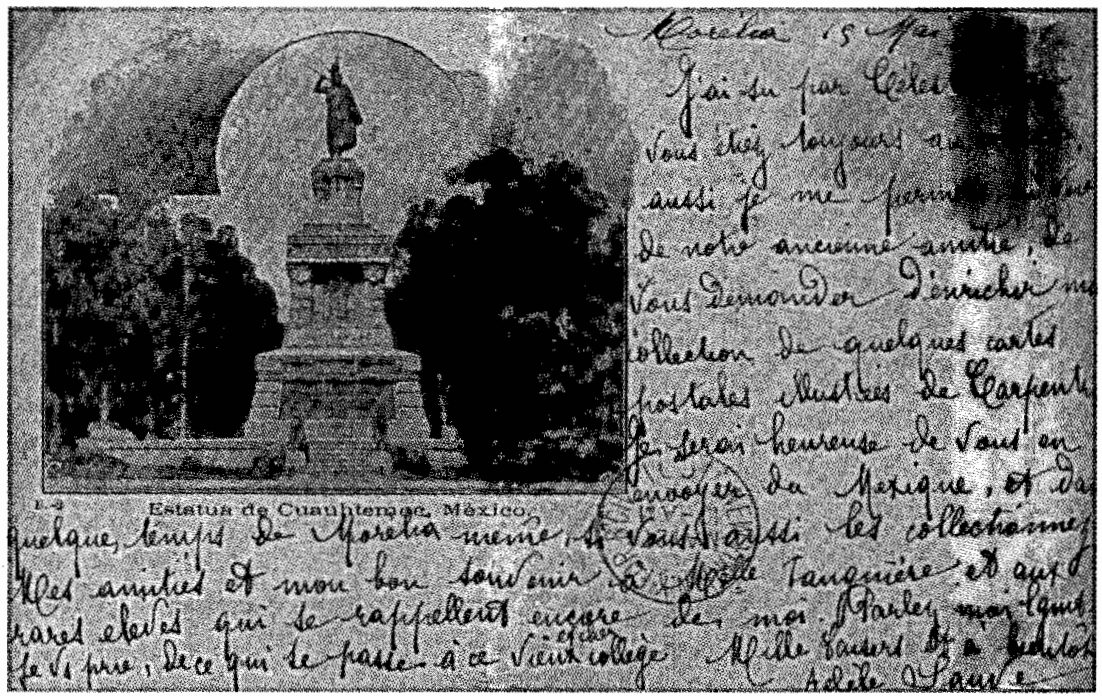


De la comparación de las posiciones exportadoras de los principales productores de tejidos de algodón (crudo, blanqueado y de color) en los mercados internacionales y en el mercado cubano emergen algunos hechos altamente significativos (véase cuadro 6). El papel hegemónico desempeñado por Inglaterra en los mercados internacionales $(66.16 \%$ de la exportación mundial) estaría muy secundado en el mercado cubano por Estados Unidos (30.18\% de la exportación a Cuba). ${ }^{22}$ Por otro lado, la cuota española sobre el mercado cubano (17.68\%) se sitúa extraordinariamente por encima de la que le corresponde en el mundo ( $0.93 \%)$, lo que supone que España, a la zaga de los exportadores mundiales, en el mercado cubano está por delante de Francia, Alemania e Italia, países con los que estaba lejos de competir en el resto de los mercados.

La independencia política de Cuba en el año 1898 habría ocasionado el fin de una estructura de monopolio colonial en favor de España, dando lugar a un nuevo entorno competitivo distinto para los productos estándar (como los tejidos de algodón blancos) y los productos diferenciados (los productos de algodón de color).

presencia de inmigrantes españoles, como es el caso argentino, el porcentaje que representaban los tejidos de algodón españoles sobre el total importado (aunque hallándose por debajo del caso cubano) indicaba una mayor competitividad que en otros mercados donde no existía una presencia importante de inmigración española.

${ }^{22}$ Este papel hegemónico de Estados Unidos en Cuba en 1913 viene explicado, además de por la proximidad geográfica, por el Tratado de Reciprocidad Tarifaria Bilateral de 1903 , que rebajaba los aranceles sobre las manufacturas de algodón estadunidense 30 por ciento.
Mientras el papel hegemónico de Estados Unidos en este nuevo entorno vendría explicado por razones geopolíticas, ${ }^{23} \mathrm{el}$ presente trabajo pretende profundizar en la posición de España en algunos productos diferenciados, en clara disonancia con las posiciones ostentadas en el ámbito internacional.

Para poder entender qué ocurre con la exportación textil española en Cuba es necesario desagregar los datos, diferenciando los tejidos de algodón blancos de los de color (véase gráfica 3). De esta forma se constata cómo los tejidos blancos, producto que puede ser considerado homogéneo y sujeto a las leyes de la competencia perfecta, tras la independencia, han perdido prácticamente su mercado en la isla. Sin embargo, los teñidos y estampados, producto claramente diferenciado, han mantenido e incrementado el volumen total de sus exportaciones a Cuba.

Este fenómeno pone de relieve el impacto de la nueva naturaleza del mercado cubano, es decir, del aumento de competencia sobre la estrategia comercial de España, caracterizada por la diferenciación de los productos exportados. Esta estrategia, alternativa a la competencia por el precio, no se limita al caso de los tejidos de algodón, sino que parece repetirse también en otras categorías de productos consideradas. El caso de las alpargatas, producto que encuentra en Cuba un mercado que absorbe el grueso de sus exportaciones, parece seguir las mismas pautas que los tejidos de algodón. ${ }^{24}$

Sin embargo, como ya se ha señalado anteriormente, la diferenciación de producto no era una estrategia exclusiva de

${ }^{23}$ Zanetti, "Comercio", 1975, y Comercio, 1998.

${ }^{24}$ Véase nota 21. 
Cuadro 6. Porcentaje de la exportación mundial de tejidos de algodón

Exportadores

Inglaterra

Estados Unidos

España

Francia

Alemania

Italia
Exportación a Cuba

42.65

30.18

17.68

1.87

0.36

0.00
Exportación mundial

66.74

4.26

0.93

5.47

5.67

3.99

Fuente: Kertesz, Textilindustrie, 1917.

Gráfica 3. La exportación a Cuba de tejido español blanco y de color

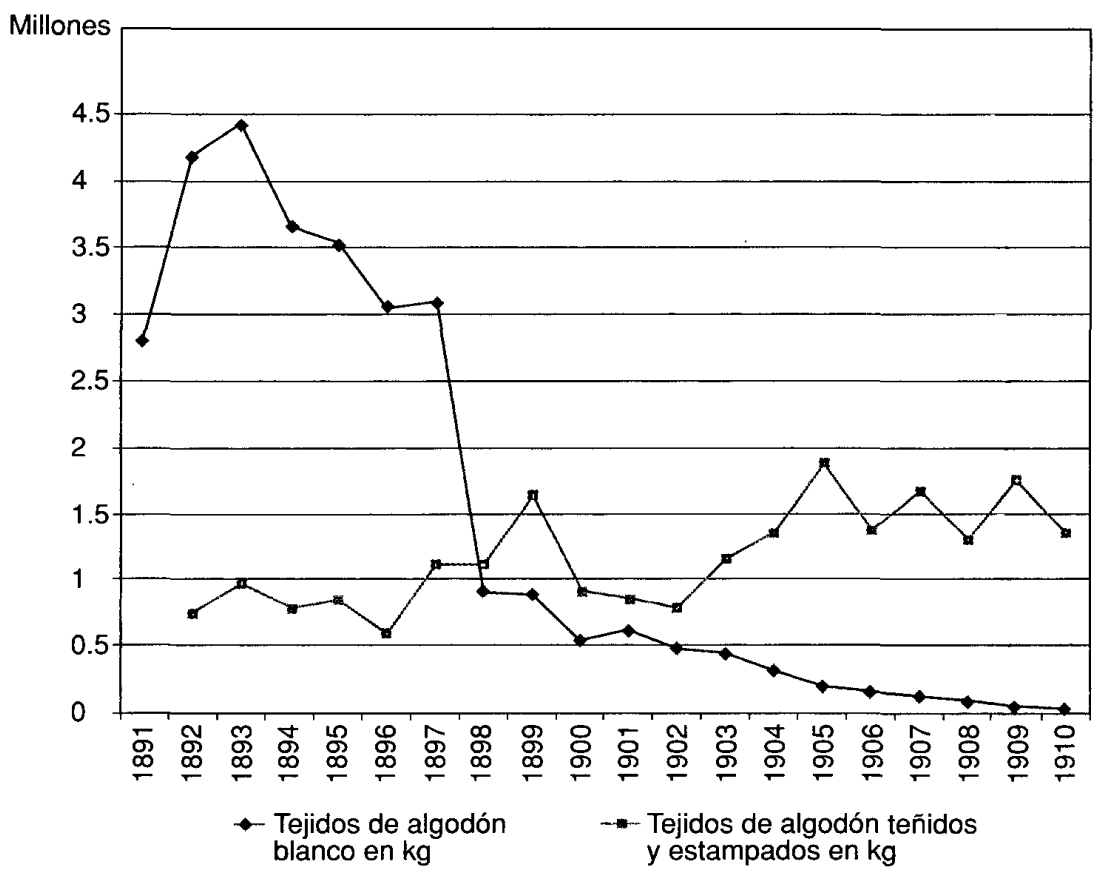

Fuente: Estadísticas del comerio exterior de España, 1891-1910. 
España, sino que era ampliamente utilizada en los mercados internacionales de la época, caracterizados por un aumento de la competencia. Los datos de las exportaciones de tejidos de algodón en 1913, que distinguen entre la exportación total y la de los tejidos de color, muestran la especialización en esta categoría de producto de los principales países exportadores (véase cuadro 7).

El peso de los tejidos de color en el comercio internacional de tejidos de algodón era de $50.08 \%$ en 1913 . Entre los principales exportadores sólo Estados Unidos, Gran Bretaña y Suiza tenían porcentajes superiores de exportación de tejido crudo y blanco, lo que pone de relieve que en el caso de claras ventajas de costes, la diferenciación no era el elemento esencial. Sin embargo, para el resto de los exportadores, sin posibilidades de competir vía costes con los líderes mundiales, la especialización en tejidos de color (tintados, estampados o multicolores) resulta crucial. Destaca el caso de Turquía y España, con una exportación de tejido de color por encima de 90 por ciento.

\section{PERVIVENCIAS HISTÓRICAS Y COMPETITIVIDAD DEL TEXTII ESPAÑOL}

La competitividad de los productos textiles españoles es un tema en debate en la historiografía española. ${ }^{25}$ En el caso cubano, la persistencia en el tiempo de rela-

\footnotetext{
${ }^{25}$ Véase al respecto: Prados, "Evolución", 1984; Fraile, Industrialización, 1991; Tena, "Protección", 1992; Nadal y Sudrià, "Controversia", 1993; Sudrià, "Empresa", 1999, y Prat y Soler, "Formación", 2002, entre otros.
}

ciones comerciales y la presencia de estrategias de diferenciación para superar problemas de competitividad en costes representan una clara anomalía respecto al papel desempeñado por España en el panorama internacional. Abordar esta cuestión desde un enfoque de demanda puede arrojar nueva luz al debate, tradicionalmente centrado en el análisis de la oferta.

La abrupta disminución de la exportación de tejidos blancos (véase gráfica 3) pone de manifiesto la falta de competitividad de la industria española en un producto fundamentalmente estandarizado, donde la ventaja en los costes de producción podía ser determinante. En contraposición, el aumento de la exportación de tejido teñido y estampado ¿respondía realmente a una mayor competitividad en determinadas variedades de tejido, permitiendo superar el tan debatido problema de los mayores costes de producción de la industria textil catalana? El escaso papel internacional de los tejidos españoles, incluyendo los de color, da una respuesta clara a esta interrogante: los tejidos españoles no eran competitivos en costes de producción, ni siquiera con estrategias de diferenciación de producto. ¿Cómo se explica entonces la exportación a Cuba?

En el presente trabajo se sugiere que el caso cubano no es un ejemplo de adaptación competitiva de la industria exportadora española, sino que fueron las características específicas del mercado cubano las que permitieron un éxito exportador tan localizado. Si bien queda clara la pérdida del dominio español, sobre todo en relación con Inglaterra y Estados Unidos, el mantenimiento de cuotas de mercado considerablemente por encima de Francia, Alemania e Italia puede contemplarse como una pervivencia histórica de su pa- 
Cuadro 7. Composición de la exportación de tejidos de algodón (1913)

$\begin{array}{lcc}\text { Exportaciones } & \begin{array}{c}\text { Porcentaje sobre la } \\ \text { exportación mundial }\end{array} & \begin{array}{c}\text { Porcentaje dedicado } \\ \text { al tejido de color }\end{array} \\ \text { Turquía } & 0.02 & 94.92 \\ \text { España } & 0.93 & 91.89 \\ \text { Austria-Hungría } & 2.20 & 83.99 \\ \text { Finlandia } & 0.13 & 80.05 \\ \text { Portugal } & 0.11 & 79.81 \\ \text { Italia } & 3.96 & 79.12 \\ \text { Rusia } & 3.31 & 79.03 \\ \text { Alemania } & 5.62 & 78.21 \\ \text { Bélgica } & 2.23 & 73.20 \\ \text { Francia } & 5.42 & 65.79 \\ \text { India británica } & 1.00 & 64.27 \\ \text { Dinamarca } & 0.06 & 56.29 \\ \text { Holanda } & 2.94 & 55.88 \\ \text { Suiza } & 0.82 & 49.15 \\ \text { Gran Bretaña } & 66.16 & 41.41 \\ \text { Estados Unidos } & 4.23 & 40.35\end{array}$

Fuente: Kertesz, Textilindustrie, 1917.

sado colonial. ${ }^{26}$ Una manera de argumentar esta hipótesis consiste en analizar la demanda cubana y española para los tejidos de algodón de color.

Llegados a este punto es necesario plantear la distinta naturaleza de la diferenciación: la diferenciación de producto vertical, es decir, consecuencia de distintos niveles de calidad del producto, y la diferenciación de producto horizontal, es decir, de variedades diferenciadas de un mismo producto final. Esta distinción es

${ }^{26} \mathrm{Al}$ establecer el contraste cuantitativo por medio de modelos gravitacionales del peso del pasado colonial sobre el comercio puede encontrarse en Eichengreen e Irwin, "Role", 1996, para el periodo 1949-1964, y en Carreras, "Mercado", 2001, para el comercio textil en 1913. relevante debido a que mientras en el primer caso la présencia de diferenciación remite a los niveles de renta y permite el uso de modelos basados en las dotaciones factoriales, en el caso de la diferenciación horizontal se remite a la preferencia de los consumidores, una variable mucho más difícil de captar y cuantificar, relacionada con los modelos de competencia imperfecta y las teorías del consumo.

El cuadro 8 recoge los destinos de la exportación española de tejidos de algodón de color en 1913. En primer lugar, destaca el dominio absoluto, exceptuando Turquía, de América Latina como de destino de la exportación de esta categoría de producto. Este fenómeno apunta a que el idioma común, indirectamente relacionado con el pasado compartido, puede ser 
Cuadro 8. La exportación española de tejidos de algodón de color (pesetas de 1913)

$\begin{array}{ccc}\text { Consumo textil } & \text { Intensidad de } \\ \text { Población } & \text { exportación } & \text { importación }\end{array}$

$\begin{array}{lrrrr}\text { Cuba } & 2.47 & 27.19 & 10.00 & 4.05 \\ \text { Uruguay } & 1.18 & 39.65 & 1.38 & 1.17 \\ \text { Argentina } & 7.73 & 60.13 & 6.00 & 0.78 \\ \text { Chile } & 3.55 & 41.50 & 1.00 & 0.28 \\ \text { México } & 15.20 & 21.54 & 2.38 & 0.16 \\ \text { Colombia } & 5.07 & 13.33 & 0.70 & 0.14 \\ \text { Venezuela } & 2.75 & 10.20 & 0.35 & 0.13 \\ \text { Turquía } & 23.80 & 27.71 & 2.63 & 0.11 \\ \text { República Dominicana } & 3.21 & 7.60 & 0.26 & 0.08 \\ \text { Perú } & 5.60 & 9.58 & 0.25 & 0.04 \\ \text { América Central } & 5.35 & 13.23 & 0.18 & 0.03\end{array}$

${ }^{a}$ Millones de personas.

${ }^{\mathrm{b}}$ Millones de pesetas.

Fuente: Kertesz, Textilindustrie, 1917.

un factor relevante en el éxito de la exportación española. En segundo lugar, se pone de manifiesto el dominio de Cuba, que recoge $38.5 \%$ del tejido español exportado (en términos absolutos). El dominio de la isla todavía se pone más de relieve tras considerar el tamaño de los países de destino, con lo que resulta una intensidad de la importación cubana de tejido español de 4.05 pesetas de 1913, muy por encima del resto de los países importadores.

Mientras la intensidad importadora cubana alcanza valores máximos, su posición relativa en términos de similitud de consumo textil per cápita con el mercado español ocupa una posición menos destacada con $74 \%$ del consumo español (de 36.99 pesetas), después de países como Uruguay (107\%), Chile (112\%) y Turquía (75\%). Si la variable clave en la ex- portación fuese un nivel de renta similar, caeteris paribus, debería haberse importado mucho más tejido español en Uruguay, Chile y Turquía, y mucho menos en países con clara divergencia de renta como Argentina. Ello hace pensar que la estrategia de diferenciación explicativa de la competitividad del tejido español en Cuba podría haber sido de tipo horizontal, es decir, basada en una similitud de preferencias entre ambos mercados. No disponemos de información cuantitativa fiable para contrastar esta hipótesis, pero contamos, sin embargo, con información cualitativa al respecto, a partir de fuentes americanas y españolas de la época. Por ejemplo, un informe comercial estadunidense de 1910 lo expresa del siguiente modo: "Spanish stripes (Guayabera Catalana) is one article that is imported by all 
merchants, who claim, however, that there is no profit in the sale. They import it on account of the patriotic demand for it by the Spanish element." 27

De este modo, pensamos que si bien existe una cierta afinidad en términos de consumo textil per cápita entre el mercado cubano y el mercado español, este elemento resulta insuficiente para explicar la persistencia de la relación comercial hispano-cubana, siendo las preferencias de los consumidores el posible elemento clave. ¿Cómo explicar ahora la presencia de estas preferencias coincidentes entre ambos mercados? Una respuesta plausible viene dada porque un segmento importante del mercado cubano estaba constituido por consumidores cubanos de ascendencia española o asimilados a los gustos de la antigua metrópoli, y por emigrantes -españoles demandantes de tejidos españoles. Esta hipótesis se hace difícil de contrastar mediante métodos cuantitativos, de modo que sus fundamentos se encuentran en la información cualitativa coetánea, a través de los informes comerciales de la época. ${ }^{28}$

Por otro lado, la importancia del elemento patriótico en las relaciones comerciales hispano-cubanas a través de los flujos migratorios era también claramente percibida desde la península, tal y como se pone de manifiesto en un manual comercial de 1908: "Los inmigrantes españoles en las repúblicas hispanoamericanas, cuyo número excede de un 1000000 , son auxiliares eficacísimos de la importación española." ${ }^{29}$

${ }^{27}$ Graham, "Cotton", 1910, p. 12.

${ }^{28}$ Véanse al respecto, Odell, Cotton, 1911; Witham, "Reporr", 1907, y Report, "Cotton", 1912, vol. 1. ${ }^{29}$ Olascoaga, Relaciones, 1908.
Las cifras de la emigración a Cuba ponen de manifiesto la importante entrada de españoles a la isla. El principal grupo de inmigrantes, entre 1900 y 1910 , provenía de España y supuso más de $80 \%$ del total. Aunque sus orígenes generalmente eran rurales (fundamentalmente de Gralicia y Asturias), en Cuba se dirigieron a las ciudades atraídos por la influyente colonia española en el sector comercial cubano. ${ }^{30}$ En el año 1913, Cuba todavía era el tercer destino en importancia de la emigración española a América con $17.4 \%$ del volumen total, por detrás de Argentina $(59.55 \%)$ y Brasil $(17.55 \%){ }^{31}$

Los datos disponibles indican que en 1899 la colonia española en Cuba representaba aproximadamente $8 \%$ de la población total; ${ }^{32}$ después de la independencia la emigración española a Cuba, lejos de disminuir, aumentó significativamente. En favor de la incidencia de la emigración sobre la exportación cabe señalar que, mientras Cuba era el primer destino de la exportación española de tejidos de algodón de color, Argentina era el segundo. De la misma manera, hay que considerar que si bien los italianos superaban a los españoles en esta partida de expor-

${ }^{30}$ Los trabajos sobre emigtación son numerosos, entre otros pueden consultarse: Hernández, Emigración, 1987; Naranjo, Campo, 1988; Alonso, Consideraciones, 1993; Yáñez, Emigración, 1994; Iglesias, "Características", 1988.

${ }^{31}$ Datos sobre emigración recogidos en Yáñez, Emigración, 1994 y Sánchez-Albornoz, Población, 1973.

${ }^{32}$ Coralia Alonso Valdés, "La inmigración española en Cuba como fuerza de trabajo: 1800-1933", en línea <http://136.142.158.105/Lasa2000/Alonso Valdes.pdf>, Archivo Nacional de Cuba, La Habana, 2000. 
tación, también lo hacía la colonia de italianos en Argentina.

Por otro lado, si bien la emigración a Argentina acabaría superando a la cubana en términos absolutos, cosa que no tendría un efecto paralelo en la exportación, un elemento diferencial en Cuba sería el carácter exclusivo de los españoles. Mientras que en Argentina la colonia española convivía con fuertes contingentes de población de diversas procedencias, en la isla el elemento español era hegemónico. En 1900, dos años después de la independencia cubana, Argentina recogía 43\% de la emigración española a América, no muy lejos de Cuba adonde se dirigían $37 \%$ de los españoles emigrados a América; pero mientras que los emigrantes españoles aquel año representaban $0.43 \%$ de la población de Argentina, en Cuba los españoles entrados aquel año constituyeron $1 \%$ de la población en la isla. Por otro lado, hacia 1910 los españoles eran $77.62 \%$ de los extranjeros entrados en Cuba, pero sólo $37 \%$ de los que iban a Argentina.

Brasil podría parecer una excepción en la relación entre emigrantes y exportación, pero cabe señalar que en este caso el elemento del idioma se encontraría ausente, pues contrarrestaba el peso de esta relación. Estos datos avalan en cierta medida los comentarios recogidos en los informes comerciales de la época, a pesar de que no permiten realizar afirmaciones concluyentes acerca de la influencia de la emigración española sobre las preferencias del mercado cubano.

Tanto la emigración ${ }^{33}$ como los gustos transferidos a los consumidores cuba-

${ }^{33}$ La variable de la emigración se considera una variable de tipo histórico y no coetáneo, debido a nos habrían generado un proceso de histéresis que permitió mantener la exportación más allá de la ruptura del vínculo colonial. Pero no se trataría de un proceso indefinido en el tiempo. De hecho, esta situación de relativa ventaja competitiva de España en Cuba apenas si duró una década. La primera guerra mundial transformó radicalmente el panorama internacional; cualquier análisis que contemple el periodo posterior no puede aislar los efectos de la guerra sobre la estructura económica mundial.

\section{CONCLUSIONES}

El impacto de la independencia de Cuba sobre el comercio exterior hispano-cubano, en términos agregados, no deja lugar a dudas: 1898 supone un punto de ruptura en las relaciones comerciales bilaterales. Sin embargo, un análisis más detallado refleja fenómenos que contradicen la imagen ofrecida por los datos agregados. En primer lugar, la posición de Cuba como socio comercial de España, ponderada por el tamaño de los mercados importadores, arroja una intensidad comercial muy superior a la de los principales socios comerciales en 1913.

En segundo lugar, el análisis de la composición de la exportación muestra cómo, si bien algunos productos siguen la tendencia claramente decreciente de los datos agregados (tejidos de algodón blan$\cos$ ), algunas otras categorías de producto la invierten experimentando procesos de crecimiento de la exportación (tejidos de algodón de color). Este comportamien-

que responde, en última instancia, al pasado colonial. Véanse las diferencias con Brasil, por ejemplo. 


\section{SECUENCIG}

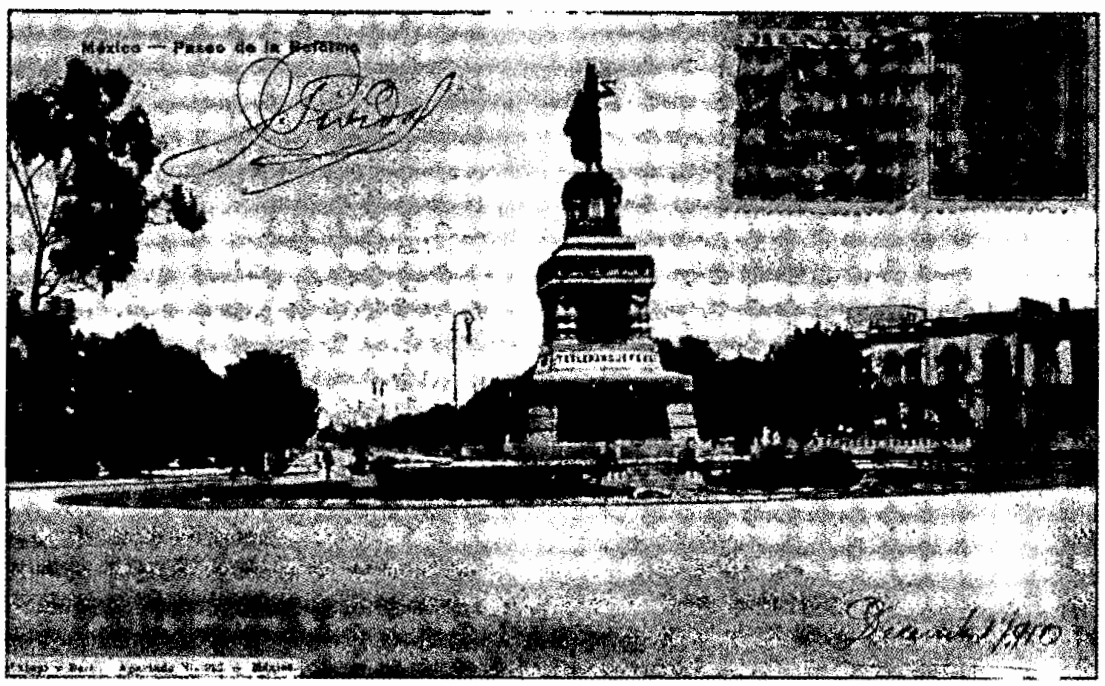


to diferencial de ciertas categorías de producto hace pensar en la presencia de dos marcos competitivos tras la independencia cubana: por un lado, un marco de competencia perfecta para los productos estándares, dominado en costes por Estados Unidos, y, por otro, una situación de competencia monopolística para los productos diferenciados, con mayores niveles de competitividad españoles.

Para explicar la persistencia de la exportación española a Cuba se ha analizado el sector de los tejidos de algodón. En esta categoría de producto el análisis de las cuotas de mercado arroja resultados sorprendentemente elevados, ya que $17.68 \%$ de la importación cubana correspondía al tejido español. Este hecho contrasta con la cuota española en los mercados mundiales, que ni siquiera significaba $1 \%$. La constatación de este dominio español en este segmento del mercado cubano constituye la principal aportación del presente trabajo. A partir de la identificación de un hecho claramente anómalo, tanto en el comercio bilateral con Cuba como en el papel de España en los mercados internacionales, se han apuntado algunas hipótesis explicativas mediante la utilización de la información cualitativa disponible.

El argumento central en la explicación de la significativa presencia española en la importación cubana se fundamenta en la estrategia de la diferenciación de producto. La literatura especializada en este sector, así como el análisis de los datos desagregados para los tejidos de color (tintados, teñidos, estampados y multicolores), pone de relieve que la diferenciación era una práctica generalizada en los mercados de la época, especialmente relevante para los países con menores cuotas de mercado, y especialmente relevante para
España en particular. Bajo este supuesto de diferenciación de producto, la competitividad del tejido de color español se atribuye no a la adaptación de la producción textil española a la demanda cubana, sino más bien a la adaptación del mercado cubano a las características específicas de los tejidos españoles, un hecho que no podría explicarse más que por su pasado de dependencia colonial.

El planteamiento de la presencia de estrategias de diferenciación horizontal (distintas variedades de un mismo producto) comporta el tratamiento de las preferencias de los consumidores cubanos en relación con los españoles. La cuantificación de esta similitud de preferencias resulta difícil de probar, pero viene avalada por los comentarios de los informes comerciales de la época, los cuales a su vez lo relacionan con la emigración española a Cuba. A pesar de que los estudios sobre el impacto de la emigración en la exportación no arrojan resultados robustos, el tamaño relativo de la colonia española sobre la población cubana podría validar este tipo de argumentos. Pero este factor no resulta suficiente para explicar la intensidad de exportación a Cuba, en la medida en que existen otros casos, siempre latinoamericanos, donde la emigración española no tiene un reflejo tan claro en la exportación como en el caso cubano.

De todo ello se concluye que la excepcionalidad del caso cubano, para los tejidos de algodón de color en concreto, respondería a un cúmulo de circunstancias cuya confluencia en la isla antillana sólo se explica por su pasado colonial. El elemento migratorio sería uno de estos factores, acompañado por el hecho de que la colonia española en Cuba tenía la exclusividad sobre el elemento extranjero, fe- 
nómeno que no se daba en Argentina. El idioma también sería un elemento añadido, en la medida en que la exportación española de esta categoría de producto queda prácticamente reducida al ámbito latinoamericano. El factor de la lengua, en cambio, desempeñaría el papel inverso en el caso brasileño, contrarrestando el posible efecto de la emigración. Todo ello configura en Cuba un escenario único, donde las preferencias del consumidor parecen ser la clave de la competitividad del tejido español.

\section{BIBLIOGRAFÍA}

-Alonso Valdés, Coralia, Consideraciones generales sobre la inmigración española: siglo XIX, Editorial de Ciencias Sociales, La Habana, 1993.

- Álvarez Valentín, Andrés, "Historia y crítica de los valores de nuestra balanza de comercio", Moneda y Crédito, núm. 4, marzo de 1943, Madrid, pp. 11-25.

- , "Las balanzas estadísticas de nuestro comercio exterior", Revista de Economía Política, vol. 1, núm. 1, 1945, Madrid, pp. 73-94.

-Blasco, Yolanda, "Exportaciones españolas a Cuba. Aproximación por productos", Actas del III Congreso de Historiadores Latinoamericanistas, Pontevedra, 2001 (formato $\mathrm{CD}$ ).

-Broadberry S. y A. Marrison, "External Economies of Scale in the Lancashire Cotton Industry, 1900-1950", Economic History Review, vol. 55, núm. 1, 2002, Londres, pp. 51-77.

-Brown, J. C., "Imperfect Competition and Anglo-German Trade Rivalry: Markets for Cotton Textiles before 1914", The Journal of Economic History, vol. 55, núm. 3, 1995, pp. 494527.

-Burenstam Linder, S., An Essay on Trade and Transformation, Almqvist \& Wicksell, Suecia, 1961.
-Carreras, Albert, "La coyuntura económica del 98" en Octavio Ruiz Manjón y Alicia Langa Laorga, Los significados del 98. La sociedad española en la génesis del siglo XX, Fundación ICO, Madrid, 1999, pp. 281-305.

-Carreras, Anna, "El mercado internacional de tejidos de algodón en 1913 y la industria española", Revista de Historia Económica, vol. 19, número extraordinario, 2001, Madrid, pp. 111127.

-David, Paul, "Clio and the Economics of QWERTY", American Economic Review, núm. 75, 1985, pp. 332-337.

, "Understanding the Economics of QWERTY: the Necessity of History" en W. Parker, Economic History and the Modern Economist, Basil Blackwell, Oxford, 1986, pp. 30-49.

-Eichengreen, B. e Irwin, D. A., "The Role of History in Bilateral Trade Flows", Working Paper 5565, National Bureau of Economic Research, 1996, p. 51.

-Estadísticas del comercio exterior de España, 1891-1910.

-Fraile, Pedro, Industrialización y grupos de presión. La economía política de la protección en España 1900-1950, Alianza Editorial, Madrid, 1991.

-Graham Clark, W. A., "Cotton Goods in Latin America. Part I Cuba, Mexico and Central America", Special Agent Series, Government Printing Office, Washington, 1910.

-Gwinner, Arturo, "La política comercial de España en los últimos decenios" en Fabián Estapé, Textos olvidados, Instituto de Estudios Fiscales, Madrid, 1973.

-Hernández García, Juan, La emigración canaria contemporánea (siglo XIX), Cabildo Insular de Gran Canaria, Las Palmas, 1987.

-Iglesias García, Fe, "Características de la inmigración española en Cuba" en Nicolás Sánchez Albornoz (ed.), Españoles bacia América y La emigración en masa, 1880-1930, Alianza Editorial, Madrid, 1988. 
-Kertesz A., Die Textilindustrie sámtlicher Staaten, Viewig \& Sohn, Braunschweig, 1917.

-Maluquer, Jordi, "Mercado colonial antillano en el siglo XIX" en Tortella y Nadal (ed.), Agricultura, comercio colonial y crecimiento económico en la España Contemporánea, Ariel, Barcelona, 1974.

- "Los economistas españoles ante la crisis del 98", Revista de Historia Industrial, núm. 12, 1997, Barcelona, pp. 11-39.

- "Las consecuencias económicas de las guerras", Revista de Occidente, núm. 202-203, 1998, Madrid.

- España en la crisis de 1898, Península, Barcelona, 1999.

-Martínez Carrión, José Miguel, "La industria de conservas vegetales en España", Revista de Historia Económica, vol. 7, núm. 3, 1989, Madrid, pp. 619-649.

-Miranda Encarnación, José Antonio, La industria del calzado en España 1860-1959. La formación de una industria moderna y los efectos del intervencionismo estatal, Generalitat Valenciana/ Instituto de Cultura Juan Gil-Albert, Alicante, 1997.

-Nadal, Jordi y Carles Sudrià, "La controversia en torno al atraso económico español en la segunda mitad del siglo XIX (1860-1913)", Revista de Historia Industrial, núm. 3, 1993, Barcelona, pp. 199-227.

-Naranjo, Consuelo, Del campo a la bodega. Recuerdos de gallegos, Ediciós Do Castro, La Coruña, 1988.

-Odell, R. M., Cotton Goods in Spain and Portugal, Government Printing Office, Washington, 1911 (Special Agent Series, núm. 46).

-Olascoaga, R., Relaciones comerciales HispanoAmericanas, Librería de Villar, Bilbao, 1908.

-Pan Montojo, Juan, "El atraso económico y la regeneración" en Juan Pan Montojo (coord.), Más se perdió en Cuba, Alianza Editorial, Madrid, 1998, pp. 261-334.
-Pinilla, V. y M. Ayuda, "The Political Economy of the Wine Trade: Spanish Exports and the International Market, 1890-1935", European Review of Economic History, núm. 6, 2002, pp. 51-85.

-Prados de la Escosura, Leandro, "La evolución del comercio exterior, 1790-1929", Papeles de Economía Española, núm. 20, 1984, Madrid, pp. 133-154.

- "Una serie anual del comercio exterior español, 1821-1913”, Revista de Historia Económica, núm. 1, 1986, Madrid. , y G. Tortella, "Tendencias a largo plazo del comercio exterior español, 1714-1913", Revista de Historia Económica, vol. 1, núm. 2, 1983, Madrid, pp. 353-406.

-Prat, Marc y Raimon Soler, "La formación de redes comerciales y el fracaso de la penetración internacional de los tejidos catalanes, 18501930", Revista de Historia Industrial, núm. 21, 2002, Barcelona, pp. 201-225.

-Ramon i Muñoz, Ramon, "La exportación española de aceite de oliva antes de la guerra civil: empresas, mercados y estrategias comerciales", Revista de Historia Industrial, núm. 17, 2000, Barcelona, pp. 97-151.

-Report of the Tariff Board, "Cotton Manufactures", vol. 1, 62d Congress, 2d Session, House Documents, Government Printing Office, Washington, 1912, 132 vols.

-Sánchez-Albornoz, Nicolás, La población de América Latina. Desde los tiempos precolombinos al año 2000, Alianza Editorial, Madrid, 1973.

-Sandberg, L. G., "Movements in the Quality of British Cotton Textile Exports, 18151913", The Journal of Economic History, vol. 28, 1968, pp. 1-27.

-Serrano Sanz, José María, “Sector exterior y desarrollo en la economía española contemporánea", Papeles de Economía Española, núm. 73, 1997, Madrid, pp. 133-155.

-Sudrià, Carles, "La exportación en el desarrollo de la industria algodonera española, 1875- 
1920", Revista de Historia Económica, vol. 1, núm. 2, 1983, Madrid, pp. 369-386.

- "La empresa española y los problemas de competitividad internacional. Una visión desde la industria algodonera", mimeo., 1999.

-Temin, Peter, "Product Quality and Vertical Integration in the Early Cotton Textile Industry", The Journal of Economic History, vol. 48, núm. 4, 1988, pp. 891-907.

-Tena, Antonio, "Comercio exterior" en Albert Carreras (ed.), Estadísticas bistóricas de España, siglos XIX-XX, Fundación Banco Exterior, Madrid, 1989.

- "Protección y competitividad en España e Italia, 1890-1960" en L. Prados de la Escosura y V. Zamagni, El desarrollo económico en la Europa del sur: España e Italia en perspectiva bistórica, Alianza Editorial, Madrid, 1992.
-Witham, W. Jr., Report on England's Cotton Industry with Brief Notes on other Industries, Department of Commerce and Labour Bureau of Manufactures, Government Printing Office, Washington, 1907.

-Yáñez Gallardo, César, La emigración española a América (siglos XIX y XX). Dimensión y características cuantitativas, Fundación Archivo de Indianos, Asturias, 1994.

-Zanetti, Oscar, "El comercio exterior de la república neocolonial", Anuario de Estudios Cubanos, Instituto Cubano del Libro, La Habana, 1975, vol. 1, pp. 45-126.

, Comercio y poder. Relaciones cubanobispano-norteamericanas en torno a 1898, Fondo Editorial Casa de las Américas, La Habana, 1998. 